\title{
Modeling of Carbon Materials Porous Structure Formation
}

\author{
Lisovskyi R. P., Poplavskyi I. O., Rachii B. I. \\ Vasyl Stefanyk Precarpathian National University \\ Shevchenko Street, 57, Ivano-Frankivsk, Ukraine, 76018 \\ e-mail: bogdan_rachiy@ukr.net
}

\author{
Lyubun Z. M. \\ Ivan Franko National University of Lviv \\ gen. Tarnavskii Street, 107, Lviv, Ukraine, 79017 \\ e-mail: zinovijlyubun@gmail.com
}

\begin{abstract}
The possibility of using multilayer neural networks to predict the properties of nanoporous carbon materials is considered.
\end{abstract}

Index Terms-nanoporous materials, multilayer neural networks, prediction of material properties.

\section{INTRODUCTION}

Nanoporous carbon materials (NCM) due to the large specific surface area and unique physical and chemical properties are widely used in various branches of science and production as catalytic, electrochemical and sorption materials. A widely developed porous structure, a large specific surface area, and a dosing chemical inertness allow carbon materials to be used in the purification of drinking and sewage water from technological contamination, soil remediation, as chemo- and enterosorbents [1, 2]. Taking into account the widespread application and despite the deep and long history of their study carbon materials are very interesting research object, because of the quite large variety of raw materials, activation methods and chemical treatment of the surface. That's why defining of optimal parameters and conditions of technological processes of chemical activation and temperature treatment of plant raw materials for porous carbon materials obtaining with predetermined parameters of the porous structure is an urgent scientific and practical task. Optimization of the methods for nanoporous carbon materials obtaining requires a large number of experiments that require significant material and time costs. Therefore, the development of a mathematical model for the dependence of the characteristic of NCM porous structure on the technological conditions of obtaining is an urgent task. Such a model development will allow predicting the properties of NCM depending on various technological parameters that will enable to determine the direction of finding the optimal characteristic of materials.

\section{METHODS}

To predict the physical properties of materials it is necessary to develop a mathematical model of a physical object with a set of input values given by the vector of input parameters $\vec{x}$ that determines the properties of the material the vector of output parameters $\vec{y}$.

Mathematical model is a system of equations (integral, differential and algebraic) that enables the vector of output parameters $\vec{y}$ to be calculated according to a given vector of input parameters $\vec{x}$.

The difficulty of physical processes in the investigated material causes significant difficulties in implementing a mathematical model with the help of mathematical dependencies in the form of a system of equations. Using the neural networks gives the possibility to avoid this problem. It should be understood that to avoid but not to solve completely. The neural network structure is taken and it is considered that after training it will play the role of a mathematical model of a physical object which then can be used for prediction. For the training of the neural network training pairs are needed (as many as possible) $\left(\vec{x}^{(i)}, \vec{y}^{(i)}\right)$, where $\vec{y}^{(i)}$ - the output vector value $\vec{y}$ for the given input $\vec{x}^{(i)}$.

The created neural network plays the role of an approximator, which makes it possible to determine the properties of the physical system at arbitrary values $\vec{x}^{(i)}$.

Neural networks are considered as versatile approximators $[3,5]$. The ability of neural networks to approximate multidimensional functions is based on Kolmogorov's theory [4]. Based on Kolmogorov's theorem, one can choose the structure of a minimal complexity neural network for approximating the arbitrary function of many variables. Kolmogorov's theorem plays an important role in the theory of neural networks. It gives the mathematical reasoning of the possibility of implementing an arbitrary multidimensional function by representing this function with the help of simpler functions.

The most versatile and most often used neural structure used to solve the approximation problem is the multilayer perceptron whose structure is shown in Fig. 1.

According to Kolmogorov's theorem the only one hidden layer with the number of neurons $2 N+1$, where $N$ is dimension of function is sufficient for approximation of an arbitrary function [4]. The calculation of the number of layers according to Kolmogorov's theorem is theoretical. For 
practical tasks, the number of hidden layers varies from $N$ to $3 N$ and a number of hidden layers to two [3].

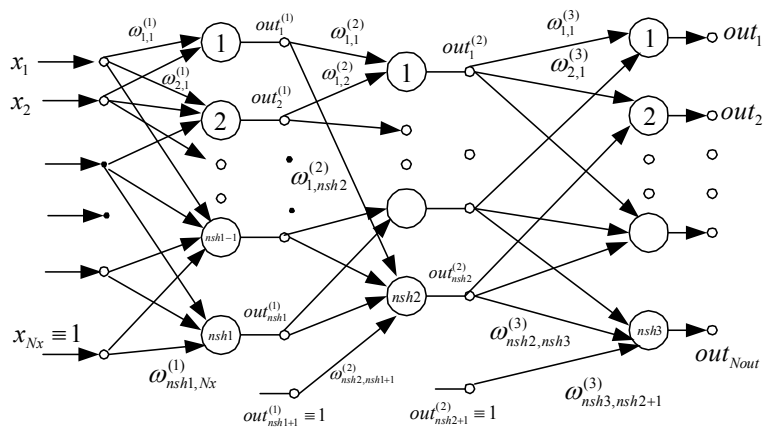

Fig.1. The structure of multilayer neural network.

Using neural networks to predict the results of measuring physical experiments has its own peculiarities and requires the preliminary processing of input data. Preliminary processing involves, if it is necessary, the removal of noise components and the normalization of data - reduction to the specified limits, usually within [0..1]. Data normalization accelerates the training process of neural networks and is necessary when using activation functions that have compressive properties. For example, the value on the output of the neuron can vary only in the range of [0..1] for sigmoid activation function.

When using the neural network for predicting, it is necessary to take into account that the predicted values on the output of the network can not exceed one.

For normalization of input and output vectors of neural network one can use the following dependence:

$$
x_{i}^{H}=\left(x_{i}-x_{\min }\right)(b-a) /\left(x_{\max }-x_{\min }\right)+a,
$$

where $x_{i}$ - non-normalized data, $x_{\max }, x_{\min }-$ maximum and minimum value from input data array, $b, a$ - upper and lower limit of normalized data, respectively.

The reverse operation for returning to real physical parameters is carried out according to the formula:

$$
x_{i}=\left(x_{i}^{H}-a\right)\left(x_{\max }-x_{\min }\right) /(b-a)+x_{\min } .
$$

\section{III.RESULTS AND DISCUSSION}

For the training of the neural network the characteristics of porous structure of NCM $\left(\mathrm{S}_{\mathrm{BET}}\right.$ - total surface area, $\mathrm{S}_{\text {meso }}-$ mesopore area, $\mathrm{S}_{\text {micro }}$ - micropore area) were used. They are obtained based on adsorption / desorption isoterms analysis of nitrogen at the boiling temperature $\left(-196^{\circ} \mathrm{C}\right)$ [6] and are shown in Table 1.

Series of samples (Table 1) is denoted according to acid mass/precursor mass ratio and activation temperature. For example, BK-150-450 is the material, that is obtained by mixing of acid and precursor in the ratio of 1:1.5 and activated at the temperature of $450{ }^{\circ} \mathrm{C}$.

For the approximation of these dependencies the threelayer perceptron with sigmoid activation function was used. Trained network was used for predicting of values $S_{\text {meso }}$ and

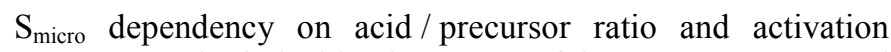
temperature both inside the range of input parameters and outside.

TABLE I.

\begin{tabular}{|c|c|c|c|}
\hline \multirow{2}{*}{ Sample } & \multicolumn{3}{|c|}{ Specific surface } \\
\cline { 2 - 4 } & $\begin{array}{c}\mathrm{S}_{\mathrm{BET}}, \\
\mathrm{m}^{2} / \mathrm{g}\end{array}$ & $\begin{array}{c}\mathrm{S}_{\text {meso }} \\
\mathrm{m}^{2} / \mathrm{g}\end{array}$ & $\begin{array}{c}\mathrm{S}_{\text {micro }} \\
\mathrm{m}^{2} / \mathrm{g}\end{array}$ \\
\hline BK-025-450 & 767 & 41 & 726 \\
\hline BK-025-500 & 948 & 95 & 853 \\
\hline BK-025-550 & 754 & 48 & 706 \\
\hline BK-050-450 & 1519 & 275 & 1244 \\
\hline BK-050-500 & 1219 & 138 & 1081 \\
\hline BK-050-550 & 1270 & 181 & 1089 \\
\hline BK-075-450 & 1825 & 530 & 1295 \\
\hline BK-075-500 & 1668 & 565 & 1103 \\
\hline BK-075-550 & 1990 & 595 & 1395 \\
\hline BK-100-450 & 1818 & 664 & 1154 \\
\hline BK-100-500 & 1754 & 744 & 1010 \\
\hline BK-100-550 & 1972 & 1029 & 943 \\
\hline BK-125-450 & 1192 & 559 & 633 \\
\hline BK-125-500 & 1192 & 769 & 423 \\
\hline BK-125-550 & 1415 & 1023 & 392 \\
\hline BK-150-450 & 1118 & 567 & 551 \\
\hline BK-150-500 & 1154 & 719 & 435 \\
\hline BK-150-550 & 1061 & 729 & 332 \\
\hline BK-175-450 & 856 & 399 & 457 \\
\hline BK-175-500 & 1099 & 809 & 290 \\
\hline BK-175-550 & 1275 & 923 & 352 \\
\hline BK-200-450 & 1187 & 780 & 407 \\
\hline BK-200-500 & 1173 & 905 & 268 \\
\hline BK-200-550 & 1216 & 952 & 264 \\
\hline
\end{tabular}

Fig. 2 shows the dependence of $\mathrm{S}_{\text {meso }}$ on acid/precursor ratio and activation temperature based on experimental data (Table 1).

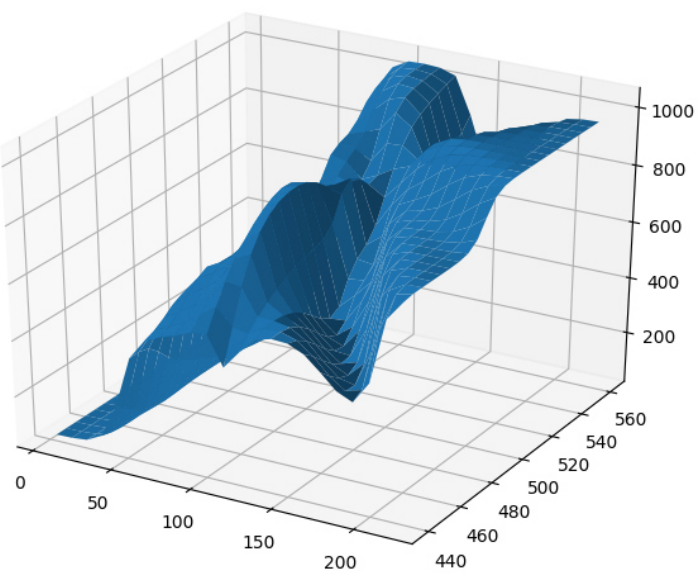

Fig.2. The dependence of mesopore area on acid / precursor ratio.

Approximations that can be used for $\mathrm{S}_{\text {meso }}$ predicting in the range of experimental research are shown in Fig. 3. 


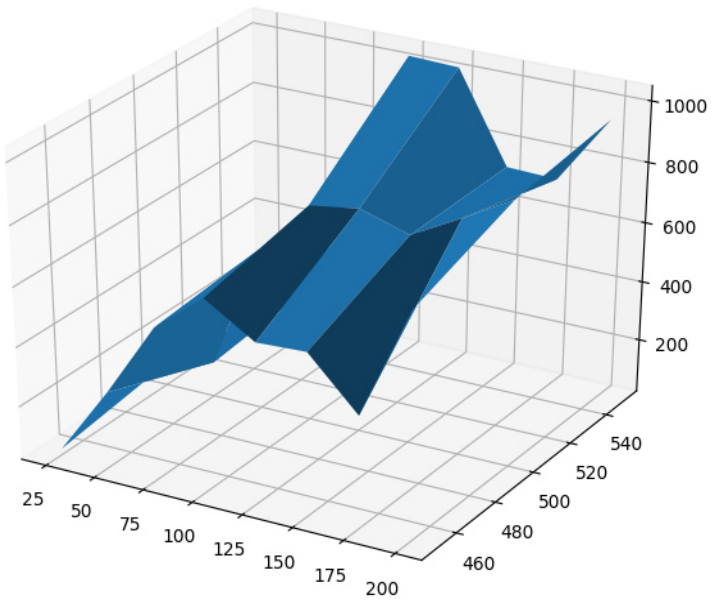

Fig.3. Predicting dependency of mesopore area on acid / precursor ratio in the range of experimental data.

Using of the obtained neural network model in extended region of output parameters outside the experiments is shown in Fig. 4.

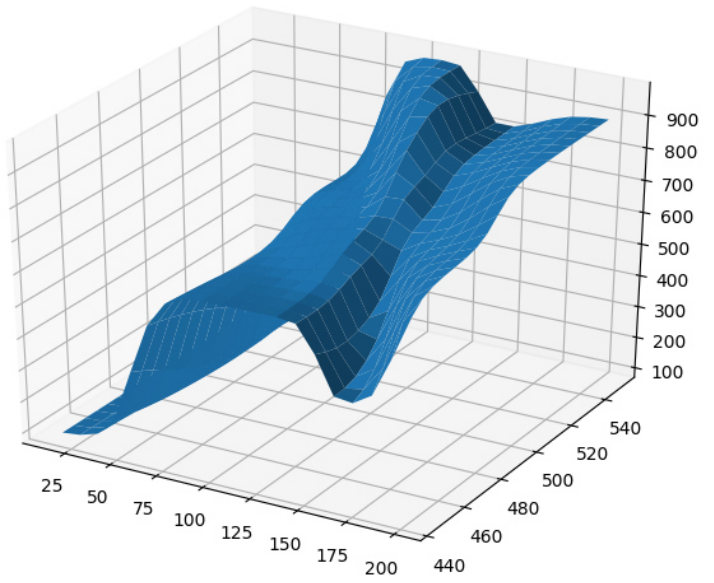

Fig.4. Predicting dependence of mesopore area on acid / precursor ratio outside the range of experimental data.
Neural network model allows calculating optimal input parameters, for example, maximal value $S_{\text {meso }}=1035 \mathrm{~m}^{2} / \mathrm{g}$ can be expected to obtain at acid / precursor ratio of 1.22 and at the activation temperature of $527^{\circ} \mathrm{C}$.

\section{CONCLUSIONS}

Thereby, based on numerical experiments they can assume the multilayer neural network may be used for the prediction of physical properties of nanoporous carbon materials.

\section{REFERENCES}

[1] New Nanoporous Biocarbons with Iron and Silicon Impurities: Synthesis, Properties, and Application to Supercapacitors / R.Ya.Shvets, I.I. Grygorchak, A.K. Borysyuk, S.G. Shvachko, A.I. Kondyr, V.I. Baluk, A.S. Kurepa, and B.I. Rachiy // Physics of the Solid State. 2014. - Vol. 56, No.10. - pp. 2021-2027.

[2] A composite of nanoporous carbon and thermally exfoliated graphite as an effective electrode material for supercapacitors / B. I. Rachiy, I. M. Budzulyak, E. A. Ivanenko, S. L. Revo // Surface engineering and applied electrochemistry. - 2015. - Vol. 51, № 5, pp. 501-508.

[3] Осовский С.Нейронные сети для обработки информации/ Пер. с польского И. Д. Руданского. М.: Финансы и Статистика, 2002.344с.:ил.

[4] Колмогоров А.Н. О представлении непрерывных функций нескольких переменных в виде суперпозиции непрерывных функций одного переменного // Докл. АН СССР. 1957. Т. 114, №5.C. 953-956.

[5] Funahashi K. On the Approximate Realization of Continuous Mappings by Neural Networks // Neural Networks, 1989.-v.2, № 3.-P183-192.

B.I. Rachiy, B.K. Ostafiychuk, I.M. Budzulyak, N.Ya. Ivanichok. Specific energy characteristics of nanoporous carbon activated by orthophosphoric acid // Journal of Nano- and Electronic Physics. - 2015. V. 7, № 4. - p. 040077(6). 